\title{
Increasing tumoral 5-fluorouracil concentrations during a 5-day continuous infusion: a microdialysis study
}

\author{
Inge R. H. M. Konings • Stefan Sleijfer • Ron H. J. Mathijssen • Peter de Bruijn • \\ Inge M. Ghobadi Moghaddam-Helmantel $\cdot$ Linda M. van Dam • \\ Erik A. C. Wiemer · Jaap Verweij · Walter J. Loos
}

Received: 11 May 2010 / Accepted: 6 July 2010 / Published online: 23 July 2010

(C) The Author(s) 2010. This article is published with open access at Springerlink.com

\begin{abstract}
Purpose Response to anticancer therapy is believed to be directly related to the concentration of the anticancer drug in the tumor itself. Assessment of intra-tumor drug pharmacokinetics can be helpful to gain more insight into mechanisms involved in the (in)sensitivity of tumors to anticancer therapy. We explored the pharmacokinetics of 5-fluorouracil in both plasma and tumor tissue during a 5-day continuous infusion of 5-fluorouracil in patients with cancer. Sampling for measurement of 5-fluorouracil in tumor tissue was performed using microdialysis.

Experimental design In seven patients with an accessible (sub)cutaneous tumor treated with a continuous 5-fluorouracil infusion, plasma and microdialysate samples from tumor and normal adipose tissue were collected over a period of 5 days.

Results For six patients, drug concentrations in both tumor tissue and plasma were available. Concentrationtime curves of unbound 5-fluorouracil were lower in tumor tissue compared to the curves in plasma, but exposure ratios of tumor tissue versus plasma increased during the 5-day infusion period. The presence of circadian rhythmicity of 5-fluorouracil pharmacokinetics in the tumor itself was demonstrated as 5-fluorouracil concentrations in tumor extracellular fluid were higher during the night than during daytime.
\end{abstract}

I. R. H. M. Konings ( $₫)$ · S. Sleijfer · R. H. J. Mathijssen ·

P. de Bruijn - I. M. Ghobadi Moghaddam-Helmantel .

L. M. van Dam · E. A. C. Wiemer · J. Verweij · W. J. Loos

Department of Medical Oncology,

Erasmus University Medical Center, Room HE-118,

's Gravendijkwal 230, 3015 CE Rotterdam, The Netherlands

e-mail: i.konings@erasmusmc.nl
Conclusion Microdialysis was successfully employed in patients with cancer during a continuous 5-day 5-fluorouracil infusion. Plasma and tumor pharmacokinetics of 5-fluorouracil differed substantially with increasing 5-fluorouracil concentrations in tumor over time, possibly resulting from a lowered interstitial fluid pressure by 5 -fluorouracil itself. This microdialysis 5-fluorouracil model might be useful to monitor the effect of drug delivery modulating strategies in future studies.

Keywords Microdialysis - Pharmacokinetics .

Target site $\cdot 5$-Fluorouracil

\section{Introduction}

Traditionally, most oncological treatment regimens and doses are based on safety profiles. It is generally assumed that the obtained pharmacokinetic profile in blood is directly related to the mentioned safety and the magnitude of antitumor response. However, the efficacy of anticancer drugs will likely depend on the maintenance of adequate unbound drug concentrations in tumor tissue rather than in plasma. Furthermore, the pharmacokinetic profile of a drug in blood may not per definition resemble its pharmacokinetic profile in tumor or normal tissue, as was demonstrated in a mouse model [1-3]. More detailed information about drug levels at the tumor site itself would therefore be helpful in optimizing oncological treatment.

In clinical oncology, evaluation of tumor and tissue disposition of drugs has become possible with the technique of microdialysis. This minimally invasive sampling method is based on the exchange of compounds from the extracellular fluid into perfusate, which runs through an inserted catheter, by diffusion through a semipermeable membrane following 
their concentration gradient. No net fluid exchange occurs during microdialysis, so prolonged continuous sampling is possible without interfering with the pharmacokinetic behavior of the drug [4]. The exiting solution, the so-called microdialysate, can be used for both pharmacokinetic and pharmacodynamic analyses.

The clinical use of microdialysis to evaluate drug disposition in tumors is of considerable interest with the recognition that insufficient drug penetration into the interstitium of solid tumors may be involved in resistance to anti-tumor drugs $[5,6]$. One of the problems associated with efficient drug delivery is the presence of increased interstitial fluid pressure, a phenomenon occurring in most solid tumors [7]. To date, several studies have been performed applying the microdialysis technique in clinical oncology with several anticancer drugs [8-14]. In most of these studies, the collected data covered only a relatively short period of time, i.e., up to a maximum of $4 \mathrm{~h}(\mathrm{~h})$, which might not be adequate to obtain useful pharmacokinetic profiles for many drugs. However, recently, we showed the feasibility of prolonged microdialysis sampling up to $48 \mathrm{~h}$ in ambulant cancer patients treated with intravenous (iv) bolus carboplatin [15].

In the present study, we investigated the feasibility of microdialysis for even a longer period of time using another drug, namely 5-fluorouracil infused continuously for 5 days. The aim was to accomplish a model that could be used in further studies to monitor the influence of coadministration of other agents on tumoral 5-FU concentrations, each patient being its own control. 5-Fluorouracil belongs to the group of the antimetabolites and is a widely used agent for the treatment of colorectal, breast and head and neck cancer [16-18]. After entering the tumor cell, 5-fluorouracil is converted into several metabolites that exert anti-tumor activity by interfering with DNA synthesis and DNA repair and by incorporation in RNA. The majority of 5-FU is inactivated by the enzyme dihydropyrimidine dehydrogenase (DPD), which is mainly found in the liver but also in other tissues such as the gastrointestinal mucosa, peripheral blood cells and tumor tissue [19]. Numerous dose regimens exist, continuous administration at $1,000 \mathrm{mg} / \mathrm{m}^{2} /$ daily for 5 days being one of the most commonly used. Given the fact that 5-fluorouracil rapidly reaches a steady state in plasma during continuous infusion, it was expected that 5 -fluorouracil concentrations could be quantitated in the microdialysates during the whole 5 times 24-h period.

The aims of the present study were to explore the feasibility of continuous microdialysis sampling over a 5-day period, to assess differences in plasma and tumor pharmacokinetics of 5-fluorouracil during a continuous 5-fluorouracil infusion and to set up a clinical model, with 5-fluorouracil as model drug, for future drug delivery modulating studies.

\section{Patients and methods}

Patient selection criteria

Patients who had a (sub)cutaneous primary tumor or metastasis and for whom 5-fluorouracil-based therapy was considered a viable treatment option were eligible for the study. The (sub)cutaneous lesion had to be of sufficient size (i.e., $\geq 20 \mathrm{~mm}$ ) and readily accessible for catheter implantation. Other inclusion criteria included: no use of therapeutic doses of anti-coagulants (prophylactic use was allowed); WHO performance status $\leq 1$; age $\geq 18$ years; absolute neutrophil count $\geq 1.5 \times 10^{9} / 1$; absolute platelet count $\geq 100 \times$ $10^{9} / 1$; creatinine clearance $\geq 60 \mathrm{ml} / \mathrm{min}$; no other serious illness or medical unstable condition requiring treatment or a history of psychiatric disorder that would prohibit the understanding and giving of informed consent. This singlecenter study was approved by the ethical committee of the Erasmus Medical Center (Rotterdam, the Netherlands) and was performed in accordance with standards laid down in the 1964 Declaration of Helsinki and its later amendments. All patients gave written informed consent. (EudraCT number: 2006-001070-24).

\section{Administration of 5-fluorouracil}

5-Fluorouracil (Ebefluoro, EBEWE Pharma, Belgium) was started as a 5-day continuous intravenous infusion on day 1, at a dose of $1,000 \mathrm{mg} / \mathrm{m}^{2} /$ day. To prevent allergic reactions, nausea and vomiting, a premedication schedule consisting of dexamethasone and granisetron was administered intravenously prior to the start of the 5-fluorouracil infusion. In case 5-fluorouracil was combined with another cytotoxic, this second agent was administered only on the last day of treatment.

Plasma pharmacokinetic and microdialysis sampling were performed during a single treatment course of five days.

Microdialysis procedures

The microdialysis catheters (CMA 63 catheters, membrane length $10 \mathrm{~mm}$, molecular weight cut-off level of $\sim 20,000 \mathrm{Da}$ ), pumps (CMA 107, flow rate adjustable) and microdialysis consumables were purchased from CMA/ Microdialysis AB (Solna, Sweden). On day 0, each patient had one microdialysis catheter inserted in a suitable (sub)cutaneous tumor lesion and a second one into healthy abdominal subcutaneous adipose tissue. Catheter insertion procedures have previously been described in detail [20]. The intratumoral location of the probe tip was verified by ultrasound.

As microdialysis is not performed under equilibrium conditions, the concentration of the drug in the dialysate 
may be different from that in the fluid surrounding the probe [21]. To correct for this difference, the relative recovery of each probe was assessed the morning after the implantation of the probes by retrodialysis with $1 \mu \mathrm{g} / \mathrm{ml}$ of 5-FU in Ringer's solution as described recently [15], at a flow rate of $0.5 \mu 1 / \mathrm{min}$ (i.e., the flow rate as used during the pharmacokinetic sampling).

Prior to the clinical study, in vitro recovery experiments (data not shown) were conducted to demonstrate that 5-fluorouracil does not irreversibly bind to the catheters, the probe recovery is independent of the concentration and is equal in both directions over the probe, similar to previous studies [15].

During the pharmacokinetic experiment, samples were collected during the following sample periods: $0-2 \mathrm{~h}, 2-5 \mathrm{~h}$ following the start of infusion and subsequently every $5 \mathrm{~h}$ till the end of infusion at day 5. The 5-hour interval was chosen as at a flow rate of $0.5 \mu \mathrm{l} / \mathrm{min}$, the vials could not be overfilled during this period. Samples were stored directly at the bedside of the patient at $T<-20^{\circ} \mathrm{C}$. The dialysates were collected by centrifugation of the microvials upside down in micro-centrifuge reaction vials for $1 \mathrm{~min}$ at $500 \mathrm{~g}$, after which they were stored at $T<-20^{\circ} \mathrm{C}$ until analysis.

\section{Blood sampling}

For 5-fluorouracil plasma pharmacokinetic analysis, blood samples were collected in the presence of lithium heparin as anticoagulant at the following time points: before start of the infusion, 1, 2, 4, 7 and $12 \mathrm{~h}$ after the start of infusion and subsequently every $12 \mathrm{~h}$ till the end of infusion at day 5 . Within $15 \mathrm{~min}$ after collection, plasma was separated by centrifugation at $3,000 \mathrm{~g}$ for $10 \mathrm{~min}$ and stored at $T<-20^{\circ} \mathrm{C}$ until analysis.

\section{Unbound fraction in plasma}

Although the free fraction of 5-fluorouracil has been reported to be $>90 \%$ [22], and plasma protein binding will have a minor influence on the tissue distribution, the percentage binding may be different between patients. Therefore, we estimated the free fraction of 5-fluorouracil in each individual patient. Aliquots of $250 \mu \mathrm{l}$ of plasma samples collected each $24 \mathrm{~h}$ during the infusion period were transferred into Microcon Ultracel YM-30 Centrifugal Filter Devices (Millipore Corp., Bedford, MA, USA) with a molecular weight cut-off level of 30,000 Da. The samples were centrifuged in a fixed angle rotor at $18,000 \mathrm{~g}$ for $30 \mathrm{~min}$. The ultrafiltrate was stored at $T<-20^{\circ} \mathrm{C}$ until analysis. The individual observed concentration in each sample was divided by the total concentration. The mean free fraction was subsequently used to estimate the free fraction in all samples collected.
5-Fluorouracil analysis

5-Fluorouracil (molecular weight 130.1) in the dialysate (and ultrafiltrate) was quantitated using liquid chromatography (LC) with tandem mass spectrometric detection (MS/ MS). Briefly, a volume of $25 \mu \mathrm{l}$ of the internal standard solution containing $500 \mathrm{ng} / \mathrm{ml} 5$-chlorouracil in water was added to $25 \mu \mathrm{l}$ of dialysate, from which aliquots of $25 \mu \mathrm{l}$ were injected into the LC (Model 2795 XC chromatograph, Waters Alliance, Mildford, MA). Chromatographic separations were achieved on a Hypercarb column $(100 \times 3 \mathrm{~mm}$ internal diameter, $5 \mu \mathrm{m}$ particle size, Thermo, Breda, the Netherlands), which was held at $T=40^{\circ} \mathrm{C}$. The mobile phase was composed of water and acetonitrile and was delivered using a linear gradient setting. The initial flow rate was $0.75 \mathrm{ml} / \mathrm{min}$ where the composition changed from $10 \%$ to $90 \%$ acetonitrile in $1 \mathrm{~min}$. In the subsequent minute, the flow rate was linearly decreased to $0.25 \mathrm{ml} / \mathrm{min}$ and kept at this rate for $6 \mathrm{~min}$ at this rate. Subsequently, the flow rate was linearly increased to $1.0 \mathrm{ml} / \mathrm{min}$ in $1 \mathrm{~min}$ and kept at $1.0 \mathrm{ml} / \mathrm{min}$ for $2 \mathrm{~min}$. Hereafter, the composition changed from $90 \%$ to $10 \%$ acetonitrile in $1 \mathrm{~min}$. The overall run time was $12 \mathrm{~min}$. Detection was performed with a Waters MicroMass Quatro Micro triple-quadropole mass spectrometer in the negative ion mode. The detector was programmed to allow the $[\mathrm{MH}]^{-}$ions of 5 -fluorouracil $(\mathrm{m} / \mathrm{z}$ $129)$ and 5-chlorouracil (m/z 145) to pass through the first quadropole and into the collision cell. The collision energy for collision-induced dissociation of 5-fluorouracil and 5-chlorouracil was set at $20 \mathrm{eV}$ and $18 \mathrm{eV}$, respectively, with argon used as collision gas at a pressure of $6 \mathrm{e}^{-3} \mathrm{mbar}$. The daughter ions of 5-FU ( $\mathrm{m} / \mathrm{z} 86)$ and 5-chlorouracil $(\mathrm{m} / \mathrm{z}$ 102) were monitored through the third quadropole. The dwell time per channel for data collection was $0.150 \mathrm{~s}$. Retention times of fluorouracil and 5-chlorouracil were 2.5 and $3.3 \mathrm{~min}$, respectively. Calibration curves were linear from 10.0 to $1,000 \mathrm{ng} / \mathrm{ml}$. The accuracy ranged from 94.0 to $103.7 \%$, the within-run precisions were $\leq 12.9 \%$ and the between-run precisions were $\leq 2.7 \%$ at five tested concentrations, including the lower limit of quantitation of $10.0 \mathrm{ng} / \mathrm{ml}$.

Plasma 5-fluorouracil concentrations were quantitated likewise. Aliquots of $30 \mu \mathrm{l}$ plasma were extracted, after the addition of $10 \mu \mathrm{l}$ of $500 \mathrm{ng} / \mathrm{ml} 5$-chlorouracil, with $1.5 \mathrm{ml}$ ethyl acetate. Following vigorous vortex mixing for $5 \mathrm{~min}$ and centrifugation for $5 \mathrm{~min}$ at $18,000 \mathrm{~g}$, the clear supernatant was evaporated to dryness at $T=70^{\circ} \mathrm{C}$ under nitrogen. The residue was resuspended in $100-\mu 1$ aliquots of Ringer's solution, from which an aliquot of $50 \mu \mathrm{l}$ was injected into the system as described earlier. LC-MS/MS system settings were as described for dialysate. Calibration curves were linear from 20.0 to $2,000 \mathrm{ng} / \mathrm{ml}$. The accuracy ranged from 94.4 to $107.5 \%$, the within-run precisions were $\leq 7.1 \%$ and 
Table 1 Patient demographics of the six patients

${ }^{\text {a }}$ Probes in subcutaneous normal adipose tissue were all placed in the abdomen

\begin{tabular}{lllll}
\hline Patient & Age & Gender & Tumor type & Tumor probe site $^{\mathrm{a}}$ \\
\hline 1 & 60 & $\mathrm{M}$ & Melanoma & Leg \\
3 & 66 & $\mathrm{M}$ & Esophageal carcinoma & Cervical lymph node \\
4 & 52 & $\mathrm{~F}$ & Non-small cell lung cancer & Abdominal wall \\
5 & 59 & $\mathrm{M}$ & Melanoma & Axilla \\
6 & 49 & F & Muco-epidermoid carcinoma & Cervical tumor mass \\
7 & 59 & F & Breast & Supraclavicular lymph node \\
\hline
\end{tabular}

the between-run precisions were $\leq 4.1 \%$ at five tested concentrations, including the lower limit of quantitation of $20.0 \mathrm{ng} / \mathrm{ml}$.

During the analysis of the dialysates of the first 3 patients, a significant matrix effect was observed for 5-chlorouracil. The observed peak areas of 5-chlorouracil were significantly lower in dialysate samples compared to the Ringer's solution in which the calibration curve standard and quality control samples were prepared. This results in an overestimation of the 5FU concentrations in the ECF. By replacing the internal standard 5-chlorouracil by stable ${ }^{13} \mathrm{C} /{ }^{15} \mathrm{~N}_{2}$-labeled 5-fluorouracil, which elutes at the same time from the analytical column as 5FU, this to mass spectrometry related potentially occurring issue was resolved. Multiple reaction monitoring of ${ }^{13} \mathrm{C} /{ }^{15} \mathrm{~N}_{2}$ 5-fluorouracil was applied at $\mathrm{m} / \mathrm{z} 132>88$, with the cone voltage and collision energy set at 30 and $18 \mathrm{eV}$, respectively.

Individual pharmacokinetic parameters were estimated using non-weighted non-compartmental analysis using the software program WinNonLin 5.2 (Pharsight, CA, USA). As an increase in the ECF/plasma ratios was observed over time, partial AUCs were then calculated over 24-h intervals. Although sampling time points were not based on a 24-h cycle, the use of WinNonLin 5.2 allows for interpolation of AUCs.

\section{Results}

\section{Patients}

Seven patients were included in the study between April 2008 and November 2009, of which six patients were assessable for pharmacokinetic analysis of 5-fluorouracil in the extracellular fluid of tumor tissue. One patient (No 2) was not evaluable as there was not enough microdialysate left for re-analysis following the switch of the internal standard in the bioanalytical methodology. Only one patient (No 4) was evaluable for the analysis of extracellular fluid of normal tissue as probe recovery in the other patients was variable. In two patients (No 1 and 6), treatment of 5-FU was combined with carboplatin, which was administered on the last day of treatment after termination of the 5-FU infusion. A summary of demographic characteristics of the six patients assessable for pharmacokinetic analysis in the extracellular fluid of tumor tissue is presented in Table 1.

Probe recovery

The in vitro recovery was independent of the concentrations tested and the method applied (i.e., retrodialysis or extraction recovery). Furthermore, the in vitro recovery was constant over up to 10 studied days and showed that 5fluorouracil does not bind to the microdialysis catheter. For instance, at a flow rate of $1.0 \mu \mathrm{l} / \mathrm{min}$, the recovery was 91 $( \pm 2.2), 82( \pm 0.5)$ and $91( \pm 0.2) \%$ on days 1,4 and 10 , respectively. In addition, as increased interstitial fluid pressure is a well-known characteristic of several tumors $[7,23]$, we tested whether increased pressures influenced the recovery. Pressures up to $15 \mathrm{~mm} \mathrm{Hg}$ (i.e., $20 \mathrm{~cm}$ of Ringer's solution above the probe) had no effect on the recovery of 5-fluorouracil.

At a flow rate of $0.5 \mu \mathrm{l} / \mathrm{min}$, the in vivo recovery in the six patients evaluable for tumor tissue drug levels varied from 40 to $92 \%$ (Table 2) and was constant in each individual patient.

\section{Pharmacokinetics}

A summary of the pharmacokinetic data is presented in Table 2. As also depicted in Figs. 1 and 2, the 5-fluorouracil concentrations in the extracellular fluid of tumors are lower than the concentrations of unbound 5-fluorouracil in the plasma compartment. Over time, however, the difference between tumor and plasma concentrations decreased, as a result of increased tumor concentrations.

Figure 3 depicts the 5-fluorouracil concentrations in tumor extracellular fluid according to the time of sampling during the day. The tumoral 5-fluorouracil concentrations were higher during the night than during daytime. Of note, tumor ECF was not available from patient 3 at later time points due to the significant matrix effect observed for 5-chlorouracil during the initial analysis and the inability for re-analysis of the samples (all used). 
Table 2 Summary of pharmacokinetic data of 5-FU in plasma and ECF of tumor tissue

\begin{tabular}{|c|c|c|c|c|c|c|}
\hline Parameter & Patient 1 & Patient 3 & Patient 4 & Patient 5 & Patient 6 & Patient 7 \\
\hline Dose 5-fluorouracil (mg/day) & 2300 & 1890 & 1700 & 2000 & 1650 & 1500 \\
\hline \multicolumn{7}{|l|}{ Plasma unbound } \\
\hline Fraction unbound $(\%)^{\mathrm{a}}$ & $87 \pm 3.2$ & $93 \pm 11$ & $97 \pm 9.1$ & $86 \pm 8.5$ & $83 \pm 4.7$ & $88 \pm 2.7$ \\
\hline $\mathrm{AUC}_{0-120}(\mu \mathrm{g} * \mathrm{~h} / \mathrm{ml})^{\mathrm{a}}$ & 50.8 & 62.7 & 54.6 & 33.6 & 38.6 & NA \\
\hline $\operatorname{AUC}_{0-24}(\mu \mathrm{g} * \mathrm{~h} / \mathrm{ml})^{\mathrm{b}}$ & 8.79 & 11.1 & 7.39 & 7.22 & 6.25 & 6.56 \\
\hline $\operatorname{AUC}_{24-48}(\mu \mathrm{g} * \mathrm{~h} / \mathrm{ml})^{\mathrm{b}}$ & 10.6 & 11.4 & 9.83 & 7.05 & 6.58 & 7.94 \\
\hline $\operatorname{AUC}_{48-72}(\mu \mathrm{g} * \mathrm{~h} / \mathrm{ml})^{\mathrm{b}}$ & 10.2 & 11.8 & 12.4 & 6.74 & 7.39 & NA \\
\hline $\operatorname{AUC}_{72-96}(\mu \mathrm{g} * \mathrm{~h} / \mathrm{ml})^{\mathrm{b}}$ & 10.8 & 14.4 & 13.2 & 5.75 & 8.71 & NA \\
\hline $\operatorname{AUC}_{96-120}(\mu \mathrm{g} * \mathrm{~h} / \mathrm{ml})^{\mathrm{b}}$ & 10.4 & 14.1 & 11.8 & 6.79 & 9.62 & NA \\
\hline \multicolumn{7}{|l|}{ ECF tumor tissue } \\
\hline Probe recovery $(\%)^{\mathrm{a}}$ & $40 \pm 4.5$ & $89 \pm 3.4$ & $89 \pm 2.7$ & $92 \pm 2.4$ & $63 \pm 1.2$ & $92 \pm 1.2$ \\
\hline $\operatorname{AUC}_{0-120}\left(\mu \mathrm{g}^{*} \mathrm{~h} / \mathrm{ml}\right)^{\mathrm{b}, \mathrm{c}}$ & $11.0(0.22)$ & NA & $13.0(0.24)$ & $13.6(0.41)$ & $6.38(0.17)$ & 19.3 (NA) \\
\hline $\operatorname{AUC}_{0-24}(\mu \mathrm{g} * \mathrm{~h} / \mathrm{ml})^{\mathrm{b}, \mathrm{c}}$ & $1.31(0.15)$ & $1.69(0.15)$ & $0.92(0.12)$ & $2.09(0.29)$ & $0.94(0.15)$ & $2.61(0.40)$ \\
\hline $\operatorname{AUC}_{24-48}\left(\mu \mathrm{g}^{*} \mathrm{~h} / \mathrm{ml}\right)^{\mathrm{b}, \mathrm{c}}$ & $1.70(0.16)$ & $2.59(0.23)$ & $2.03(0.21)$ & $2.43(0.35)$ & $1.13(0.17)$ & $3.51(0.44)$ \\
\hline $\operatorname{AUC}_{48-72}(\mu \mathrm{g} * \mathrm{~h} / \mathrm{ml})^{\mathrm{b}, \mathrm{c}}$ & $2.23(0.22)$ & $2.60(0.22)$ & $2.49(0.20)$ & $2.96(0.44)$ & $1.24(0.17)$ & 5.05 (NA) \\
\hline $\operatorname{AUC}_{72-96}(\mu \mathrm{g} * \mathrm{~h} / \mathrm{ml})^{\mathrm{b}, \mathrm{c}}$ & $2.73(0.25)$ & NA & $3.82(0.29)$ & $2.85(0.50)$ & $1.50(0.17)$ & 4.28 (NA) \\
\hline $\operatorname{AUC}_{96-120}(\mu \mathrm{g} * \mathrm{~h} / \mathrm{ml})^{\mathrm{b}, \mathrm{c}}$ & $3.03(0.29)$ & NA & $3.69(0.31)$ & $3.26(0.48)$ & $1.58(0.16)$ & 3.87 (NA) \\
\hline
\end{tabular}

\section{Discussion}

Optimization of cancer therapy by enhancing drug delivery has become of major interest as many barriers to drug delivery are being identified, underlining the need for new therapeutic strategies increasing drug delivery to tumors. Obviously, this requires a model that can easily be applied in clinical practice and with the ability to monitor intratumoral drug concentrations. The present study addresses this need and proposes the use of microdialysis to obtain detailed information on drug concentrations at the tumor site. Earlier studies explored the applicability of microdialysis in clinical oncology with microdialysate collection with a maximum of up to $48 \mathrm{~h}$ after iv bolus administration of carboplatin [15]. In this study, we showed that microdialysis is also feasible for longer periods of time in cancer patients treated with continuous 5-fluorouracil infusion during a $5 \times 24$ h period.

Our results evidently show lower concentration-time curves at the tumor site in comparison with plasma. This is in line with the results of an earlier microdialysis study by Müller et al. where the obtained area under the curve (AUC) in tumor after a single iv administration of 5-fluorouracil was $61 \%$ of the AUC in plasma [8]. A remarkable observation in our study is the fact that the difference between plasma and tumor concentrations diminished over time, as a result of increasing 5-fluorouracil concentrations in the tumor. A possible explanation for this phenomenon may be a change in interstitial fluid pressure in the tumor. Many solid malignancies display a high interstitial fluid pressure, which causes poor uptake of anticancer drugs and has been associated with poor clinical response to treatment $[5,7]$. Mechanisms involved yielding a high interstitial fluid pressure in tumors are a high vessel permeability, inadequate lymphatic drainage, fibrosis and contraction of the interstitial matrix and a high cell density around the blood vessels [7]. Reducing tumoral interstitial fluid pressure is an attractive means to augment efficacy of antitumor drugs. In pre-clinical models, several agents have been revealed to decrease interstitial fluid pressure including dexamethasone [24, 25], imatinib [26, 27] and prostaglandin E1 [28]. Also several cytotoxic agents, including 5-fluorouracil, have shown to lower tumor interstitial fluid pressure within days [24, 29, 30]. Although the decrease in tumor interstitial fluid pressure following 4 days of 5-fluorouracil treatment in female SpragueDawley rats with induced mammary tumors was not significantly different, a reduction of $35 \%$ in interstitial fluid pressure was noted on day 5 compared to day 1 (7.2 vs. $4.7 \mathrm{mmHg}$; [24]). The increasing 5-fluorouracil concentration at the tumor site as observed in our study might also be due to the effect of 5-fluorouracil on the interstitial fluid pressure. Assuming that 5-fluorouracil enhanced its own tumor concentration due to its antitumor and thereby lowering 

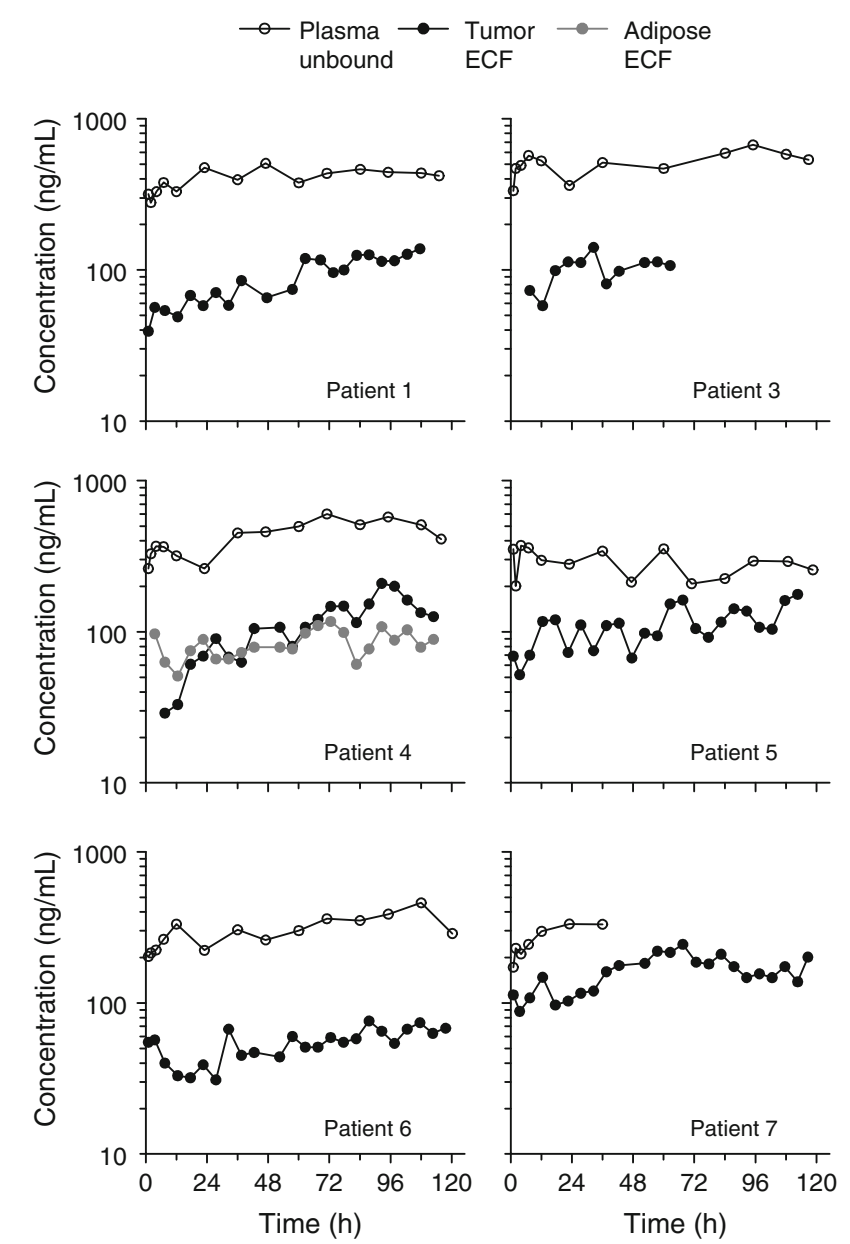

Fig. 1 Concentration-time curves of the unbound fraction of 5-FU in plasma (open circles) and extracellular fluid (ECF) of tumor (filled black circles) and ECF of normal adipose tissue (filled gray circles) in the six evaluable patients

effect on interstitial fluid pressure, our data would be in line with a recent study showing that modulation of convection currents by lowering interstitial fluid pressure by treatment with collagenase within tumors enhances the delivery of 5-fluorouracil approximately 1.5 -fold [31]. The transport of low-molecular weight compounds, such as 5-fluorouracil, from the vascular space into the interstitial space is thus also driven by convection besides by diffusion. Though only available for one patient, 5-fluorouracil uptake in normal tissue does not seem to increase over time. In the patient with evaluable pharmacokinetic data in extracellular fluid of normal tissue, the tumor exposure increased, while normal tissue exposure was constant over time (Figs. 1 and 2). This is also in agreement with the aforementioned study [31], which did not show a difference in 5-fluorouracil accumulation in normal tissue of mice treated with or without collagenase, i.e., with or without lowering of interstitial fluid pressure.

The interstitial fluid pressure and its effect on convention currents are only two of the multiple factors influencing

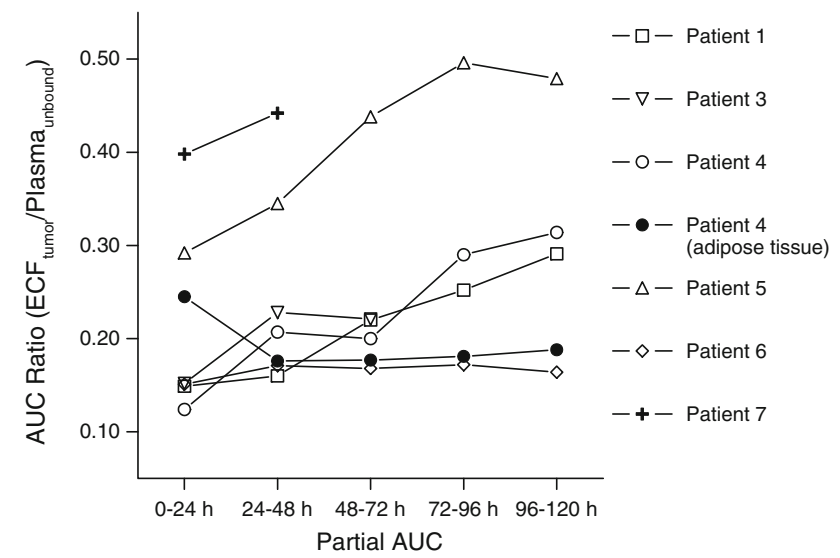

Fig. 2 Exposure ratio $\mathrm{ECF}_{\text {tumor }} /$ plasma $_{\text {unbound }}$ during the infusion of 5-FU. Each symbol represents a single patient. Patient 4 (i.e., the patient with evaluable normal tissue PK) is represented with circles. The closed circles represent the normal tissue versus plasma AUC ratio, while the open circles represent the tumor tissue versus plasma AUC ratio

drug delivery at the target site. Tumor vasculature differs significantly from that of normal tissue, with great heterogeneity in density, length and diameter, thereby impeding blood flow. Tumor $\mathrm{pH}$ gradients are of importance too, as membrane transport and accumulation of weakly acidic 5 -fluorouracil in tumors is $\mathrm{pH}$ dependent $[6,32,33]$. DPD activity may be of influence as well, since its activity is known to be variable in tumor tissue and dysregulation of DPD is more frequent in malignant tissue [19, 34]. These tumor-specific characteristics may explain the differences observed in $\mathrm{ECF}_{\text {tumor }} /$ plasma $_{\text {unbound }}$ ratio's between the patients.

Similar to the findings of our previous microdialysis study in carboplatin-treated patients measurement of 5-fluorouracil in extracellular fluid of normal adipose tissue was troublesome because of fluctuating recovery assessments [15]. It is well confirmed now that subcutaneous adipose tissue is not the best site to use as control, most probably due to its different and poorer vascularization. Other normal tissues should be chosen as site control in future studies, e.g., muscular tissue or preferably, tissue surrounding the tumor.

Another interesting observation was the typical pharmacokinetic pattern of 5-fluorouracil, with higher 5-fluorouracil tumor extracellular fluid concentrations observed during the night compared to daytime (Fig. 3). Circadian rhythmicity of 5-fluorouracil pharmacokinetics in plasma has been an issue of investigation for decades. During continuous 5-fluorouracil infusion, 5-fluorouracil plasma concentrations turned out to be higher during the night than during daytime. Many factors such as age, diet, physical activity, high serum alkaline phosphatase and length of drug infusion were previously identified as patient variables affecting 5 -fluorouracil clearance $[34,35]$. Also, dihydropyrimidine 
Fig. 3 Concentration-time curves of the unbound fraction of 5-FU in tumor ECF during day and night
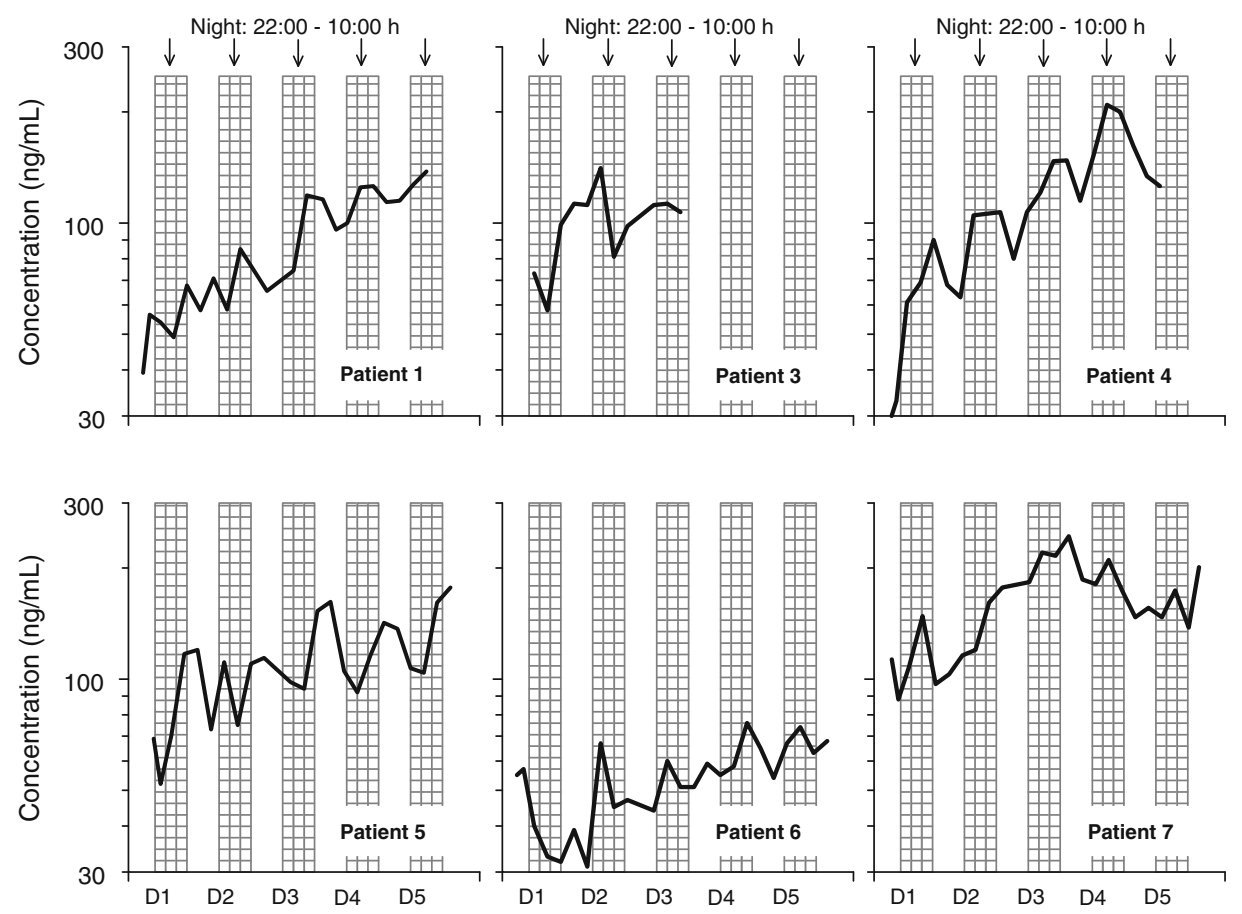

dehydrogenase activity has been found to change during the day, with its highest activity occurring during daytime [34]. In order to achieve the highest efficacy and least toxicity, chronomodulated 5-fluorouracil therapy was developed, albeit not regarded standard of care yet $[35,36]$. Our study is the first to suggest the presence of a circadian rhythm of 5-fluorouracil pharmacokinetics in the tumor itself.

In summary, we showed the feasibility of microdialysis in cancer patients treated with a continuous 5-fluorouracil infusion during a $5 \times 24 \mathrm{~h}$ period. Plasma levels of 5-fluorouracil were higher compared to tumor, but there was a distinct rise of 5-fluorouracil at the tumor site over time. Since 5-fluorouracil is a widely used cytotoxic agent and high concentrations at the tumor site are directly linked with a better response $[6,8]$, evaluation of its disposition in tumor tissue is of notable importance to further optimize individual cancer patient treatment. The technique of microdialysis can be used to improve insight into processes involved in tumor pharmacokinetics, such as interstitial fluid pressure. In a rat model, the co-administration of imatinib resulted in a significant decrease in interstitial fluid pressure with as a consequence a two to fourfold increase of the $\mathrm{ECF}_{\text {tumor }} /$ plasma $_{\text {unbound }}$ ratio's of ${ }^{51} \mathrm{Cr}$-EDTA and paclitaxel, respectively, and a significant tumor volume reduction of $44 \%$ in rats treated with 5-FU and imatinib $[26,27]$. Clinical trials investigating the impact of co-administration of drugs thought to (in)directly effect tumor drug uptake in patients with cancer are warranted, and this microdialysis model, with 5-fluorouracil as representative drug for other small molecules, might be a useful tool to study pharmacokinetics and pharmacodynamics in more detail. The ongoing development of newer microdialysis probes that can be used in deeper-lying (tumor) tissue, e.g., the liver, will add to the clinical use of this technique.

Conflict of interest The authors declare no conflicts of interest.

Open Access This article is distributed under the terms of the Creative Commons Attribution Noncommercial License which permits any noncommercial use, distribution, and reproduction in any medium, provided the original author(s) and source are credited.

\section{References}

1. Zamboni WC, Strychor S, Joseph E, Parise RA, Egorin MJ, Eiseman JL (2008) Tumor, tissue and plasma pharmacokinetic studies and antitumor response studies of docetaxel in combination with 9-nitrocamptothecin in mice bearing SKOV-3 human ovarian xenografts. Cancer Chemother Pharmacol 62:417-426

2. Zamboni WC, Strychor S, Joseph E et al (2007) Plasma, tumor, and tissue disposition disposition of STEALTH liposomal CKD602 (S-CKD602) and nonliposomal CKD-602 in mice bearing A375 human melanoma xenografts. Clin Cancer Res 13:72177223

3. Zamboni WC, Houghton PJ, Hulstein JL et al (1999) Relationship between tumor extracellular fluid exposure to topotecan and tumor response in human neuroblastoma xenograft and cell lines. Cancer Chemother Pharmacol 43:269-276

4. Müller M (2002) Science, medicine, and the future: microdialysis. Br Med J 324:588-591

5. Trédan O, Galmarini CM, Patel K, Tannock IF (2007) Drug resistance and the solid tumor microenvironment. J Natl Cancer Inst 99:1441-1454

6. Presant CA, Wolf W, Waluch V et al (1994) Association of intratumor pharmacokinetics of fluorouracil with clinical response. Lancet 343:1184-1187 
7. Heldin CH, Rubin K, Pietras K, Östman A (2004) High interstitial fluid pressure-an obstacle in cancer therapy. Nat Rev Cancer 10:803-813

8. Müller M, Mader RM, Steiner B et al (1997) 5-Fluorouracil kinetics in the interstitial tumor space: clinical response in breast cancer patients. Cancer Res 57:2598-2601

9. Mader RM, Schrolnberger C, Rizovski B et al (2003) Penetration of capecitabine and its metabolites into malignant and healthy tissues of patients with advanced breast cancer. Br J Cancer 88:782-787

10. Tegeder I, Brautigam L, Seegel M et al (2003) Cisplatin tumor concentrations after intra-arterial cisplatin infusion or embolization in patients with oral cancer. Clin Pharmacol Ther 73:417-426

11. Blochl-Daum B, Müller M, Meisinger V et al (1996) Measurement of extracellular fluid carboplatin kinetics in melanoma metastases with microdialysis. Br J Cancer 73:920-924

12. Joukhadar C, Klein N, Mader RM et al (2001) Penetration of dacarbazine and its active metabolite 5-aminoimidazole-4-carboxamide into cutaneous metastases of human malignant melanoma. Cancer 92:2190-2196

13. Ekström PO, Andersen A, Saeter G et al (1997) Continuous intratumoral microdialysis during high-dose methotrexate therapy in a patient with malignant fibrous histiocytoma of the femur: a case report. Cancer Chemother Pharmacol 39:267-272

14. Müller M, Brunner M, Schmid R et al (1998) Interstitial methotrexate kinetics in primary breast cancer lesions. Cancer Res 58:2982-2985

15. Konings IR, Engels FK, Sleijfer S, Verweij J, Wiemer EA, Loos WJ (2009) Application of prolonged microdialysis sampling in carboplatin-treated cancer patients. Cancer Chemother Pharmacol 64:509-516

16. Wolpin BM, Mayer RJ (2008) Systemic treatment of colorectal cancer. Gastroenterology 134:1296-1310

17. Seidman AD (2006) Systemic treatment of breast cancer. Two decades of progress. Oncology 20:983-990

18. Pan Q, Gorin MA, Teknos TN (2009) Pharmacotherapy of head and neck squamous cell carcinoma. Expert Opin Pharmacother 10:2291-2302

19. Kubota T (2003) 5-Fluorouracil and dihydropyrimidine dehydrogenase. Int J Clin Oncol 8:127-131

20. Müller M, Schmid R, Georgopoulos A et al (1995) Application of microdialysis to clinical pharmacokinetics in humans. Clin Pharmacol Ther 57:371-380

21. Kitzen JJ, Verweij J, Wiemer AC, Loos WJ (2006) The relevance of microdialysis for clinical oncology. Curr Clin Pharmacol $1: 255-263$

22. Czejka M, Schuller J (1992) [The binding of 5-fluorouracil to serum protein fractions, erythrocytes and ghosts under in vitro conditions] Bindung von 5-Fluorouracil an Serumproteinfraktio- nen, Erythrozyten und Ghosts unter in vitro Bedingungen. Arch Pharm 325:69-71

23. Jain RK (2001) Delivery of molecular and cellular medicine to solid tumors. Adv Drug Deliv Rev 46:149-168

24. Stuhr LEB, Salnikov AV, Iversen VV, Salvesen G, Rubin K, Reed RK (2006) High-dose, short-term, anti-inflammatory treatment with dexamethasone reduces growth and augments the effects of 5-fluorouracil on dimethyl- $\alpha$-benzanthracene-induced mammary tumors in rats. Scand J Clin Lab Invest 66:477-486

25. Kristjansen PE, Boucher Y, Jain RK (1993) Dexamethasone reduces the interstitial fluid pressure in a human colon xenograft. Cancer Res 61:6400-6415

26. Pietras K, Östman A, Sjöquist M et al (2001) Inhibition of plateletderived growth factor receptors reduces interstitial hypertension and increases transcapillary transport into tumors. Cancer Res 61:2929-2934

27. Pietras K, Rubin K, Sjöblom T et al (2002) Inhibition of PDGF receptor signaling in tumor stroma enhances antitumor effect of chemotherapy. Cancer Res 62:5476-5484

28. Salnikov AV, Iversen VV, Koisti M et al (2003) Lowering of tumour interstitial fluid pressure specifically augments efficacy of chemotherapy. FASEB J 17:1756-1758

29. Feretti S, Allegrini PR, Becquet MM, McSheehy PMJ (2009) Tumor interstitial fluid pressure as an early-response marker for anticancer therapeutics. Neoplasia 11:874-881

30. Griffon-Etienne G, Boucher Y, Brekken C, Suit HD, Jain RK (1999) Taxane-induced apoptosis decompresses blood vessels and lowers interstitial fluid pressure in solid tumors: clinical implications. Cancer Res 59:3776-3782

31. Gade TPF, Buchanan IM, Motley MW, Mazaheri Y, Spees WM, Koutcher JA (2009) Imaging intratumoral convection: pressuredependent enhancement in chemotherapeutic delivery to solid tumors. Clin Cancer Res 15:247-255

32. Peters GJ, Lankelma J, Kok RM et al (1993) Prolonged retention of high concentrations of 5-fluorouracil in human and murine tumors as compared with plasma. Cancer Chemother Pharmacol $31: 269-276$

33. Stubbs M, McSheehy PMJ, Griffiths JR, Bashford CL (2000) Causes and consequences of tumour acidity and implications for treatment. Mol Med Today 6:15-19

34. Milano G, Chamorey AL (2002) Clinical pharmacokinetics of 5-fluorouracil with consideration of chronopharmacokinetics. Chronobiol Int 19:177-189

35. Block KI, Block PB, Fox SR et al (2009) Making circadian cancer therapy practical. Integr Cancer Ther 8:371-386

36. Lévi F, Focan C, Karaboué A et al (2007) Implications of circadian clocks for the rhythmic delivery of cancer therapeutics. Adv Drug Deliv Rev 59:1015-10135 